\title{
O FENÔMENO DA AUTOCRACIA DENTRO DO PROCESSO GRUPAL
}

\author{
$*$ \\ Ângela Cruz Blauth \\ Pontífica Universidade Católica do Rio Grande do Sul - PUCRS - Brasil
}

\section{Resumo}

Buscando levantar uma reflexão acerca da autocracia operando em sistemas grupais, foi realizada uma revisão teórica a fim de esclarecer o tema, integrada juntamente à analise do filme A Onda. A experiência autocrata retratada no filme entre professor e alunos, mostra-se compatível às teorias grupais psicanalíticas, que buscam explicar como certos tipos de grupo se formam, qual a característica de seus líderes, e quais as motivações inconscientes que delineiam o funcionamento deste grupo. O presente trabalho revisitou o governo Hitler, sendo este um dos principais modelos de autocracia totalitária da história, além de ter sido tomado como base para a constituição de grupo no filme. A teoria social-histórica e a psicanálise se integram neste trabalho em uma mesma perspectiva.

Palavras Chave: Grupos, psicanálise, A Onda, Hitler, autocracia, totalitarismo.

\section{Introdução}

O conceito de autocracia, a partir dos radicais gregos, significa autos (por si próprio) e kratos (poder), ou seja, poder por si próprio. Kalsen (2000) observa que, na forma de governo autocrática, a vontade do governante é a que vale, sendo assim, a verdade absoluta pouco cede às idéias revolucionárias de mudança, a vontade de seu povo é cerceada pela vontade mais forte do governante, a Vontade Absoluta. Segundo Coelho (2010) dentro das formas de governo autocrata, pode-se configurar uma autocracia autoritária, totalitária, ou liberal. Cada um desses regimes possui características próprias, porem a semelhança mais notável é a forma de poder em que só um homem o detém, sendo um governo fechado em si próprio. Os Regimes autocráticos Liberais foram o berço da atual democracia, isso porque nos países onde autocracias liberais se encontravam estabelecidas que surgiram os primeiros governos democratas. O regime liberal é definido por regras básicas de organização de Estado, porém, coagido pela pressão das massas representou o inicio da democracia ao conferir os direitos do trabalho, da providência, da educação, saúde, salário, manipulação de moeda, etc.

Faoro (2001) procura fazer uma distinção entre autocracia autoritária e autocracia totalitária. Na autocracia autoritária o detentor do poder monopoliza o poder político sem que seja possível aos 
seus destinatários a participação real na formação da realidade estatal. Ao contrario da autocracia totalitária, o regime autoritário se satisfaz com o controle político do Estado sem pretender dominar a totalidade da vida socioeconômica da comunidade, ou determinar sua atitude espiritual. Coelho (2010) refere que o que diferencia o totalitarismo dos outros tipos de autocracia são: o regime de partido único; ideologia revolucionária; e combinação entre ideologia e terror. Em virtude de características tão peculiares e tão radicais, houve na história, poucos países que utilizaram este regime: a Itália com o fascismo de Mussolini, a Alemanha com o nazismo de Hitler e o comunismo da União Soviética, China, Coreia do Norte e Cuba.

Conforme Arendt (2012) após a primeira guerra mundial, a Alemanha entrou em crise econômica, e uma massa de homens insatisfeitos e desesperados aumentou rapidamente na Alemanha e na Áustria, o que permitiu a ascensão ao poder de Adolf Hitler. Hitler, durante toda sua vida, exerceu um fascínio que supostamente cativava a todos, e ele não poderia ter mantido a liderança de tão grande população, sobrevivido a tantas crises internas e externas, enfrentado tantos perigos de lutas intrapartidárias, se não tivesse contado com a confiança das massas.

Zimerman (2008), ao citar a teoria de Bion, fala sobre o modo de funcionamento de um grupo a partir da idéia de "suposto básico", onde o grupo se movimenta nos moldes de processo primário do pensamento, portanto, obedecem primordialmente às leis do inconsciente dinâmico. O líder é um emergente do grupo, portanto sua formação pode se dar a partir da conceituação de "supostos básicos". Há três tipos de inconscientes supostos básicos: dependência, luta e fuga, e acasalamento. No suposto-básico de dependência, o grupo espera ser sustentado por um líder de quem depende para sua alimentação material, espiritual, e proteção: neste caso, o ideal é um líder de natureza carismática. (ZIMERMAN, 1993).

Pichon Rivière (1991) descreveu quatro tipos de lideranças: autocrática, democrática, laissezfaire, e demagógica. A liderança autocrática habitualmente é exercida por pessoas de características obsessivo-narcisísticas, onde este centraliza as decisões, e impõem o seu ponto de vista, sendo própria de grupos compostos por pessoas inseguras e que não sabem fazer um pleno uso de sua liberdade.

Zimerman (1993) adiciona à teoria de Pichon Rivière um quinto tipo de liderança, trata-se do líder narcisista. Este tipo de líder costuma ser sedutor, e a empregar uma energia exuberante, por vezes carismática e toda - poderosa, que no entanto, visam sempre a manter, com os liderados, um conluio inconsciente que tem por base uma relação de poder. Tal conluio assegura aos seus liderados a gratificação de necessidades básicas, como a de garantia de proteção e amor, desde que estes reciprocamente, o alimentem continuamente com aplausos e votos de uma admiração 
incondicional.

Segundo Ávila (2009), a teoria dos grupos propõe que o indivíduo é composto por seus relacionamentos, ou seja, pelas relações que ele tem desde antes de nascer e que se somam a todas àquelas que ele constrói ao longo de sua vida. Estas relações o constituem em seu próprio aparelho psíquico, em sua identidade, em suas ações, e em tudo o que o caracteriza como sujeito. Estas são articulações da teoria psicanalítica que confirmam e fundamentam as teorias voltadas aos estudos de grupo.

Zimerman (2000) afirma que os participantes de um grupo possuem um objetivo comum e estabelecem entre si relações interpessoais. Ao mesmo tempo, o grupo também apresenta um caráter contraditório, convivendo simultaneamente com as forças de coerção e desintegração. O autor refere ser o campo grupal palco de diversos fenômenos tais como fantasias, ansiedades, e identificações, os quais se apresentam, de modo geral, no plano inconsciente. Lane (1981) refere-se ao processo grupal sendo uma experiência histórica do grupo, que se constrói em determinado espaço e tempo, fruto das relações que vão ocorrendo no cotidiano e, ao mesmo tempo, que traz, para a experiência presente, vários aspectos gerais da sociedade expressos nas contradições que emergem no grupo, articulando aspectos pessoais, características grupais, vivência subjetiva e realidade objetiva. Moraes (2001) afirma que as realidades social e individual encontram-se profundamente imbricadas, estabelecendo entre si relações circulares de troca. Portanto, os grupos estão inseridos no contexto social do qual fazem parte, trazendo para dentro de si as mesmas contradições encontradas neste contexto. Ao citar a teoria de Hanna Arendt, Bignotto (2001) mostra que o papel das massas não é sua inutilidade ou sua posição fora do processo político, mas, pelo contrário, é a sua participação no cenário político como seres facilmente manipulados pela ideologia e os movimentos totalitários.

Conforme Pichon-Rivière (1998) é através do sentimento de pertença que os indivíduos sentem-se membros efetivos de um grupo. Identificação e pertença são conceitos muito próximos. A identificação se transforma em pertença quando há uma maior integração do indivíduo ao grupo. O sentimento de pertença é compreendido por meio dos seguintes aspectos: orgulho de pertencer, sentir-se membro, sentir-se responsável, tempo no grupo e reação a crítica. Para Kaës (1997), por intermédio da mãe, a criança é colocada com o Outro, seus Outros, e seus semelhantes. O grupo é a condição de apoio do narcisismo primário. O sujeito encontra no grupo funções de suprimento analítico contra o desmoronamento dos apoios internos, um sistema de objetos garantidores contra o estado primordial de sofrimento e contra o medo de 
estar só na escuridão, um dispositivo de proteção contra a excitação traumatogena e contra a angústia.

Anzieu (2012) descreve o fenômeno de ilusão grupal, como uma fase inevitável na formação de grupos. O medo de ser grupo, e de perder sua identidade, é sem dúvida a primeira dificuldade encontrada pelos participantes. A ilusão grupal responde a um desejo de segurança, de preservação da unidade egóica ameaçada e, para tanto, ela substitui a identidade do indivíduo por uma identidade de grupo. O grupo encontra, assim, sua identidade, ao mesmo tempo em que os indivíduos nele se afirmam todos idênticos. Esse fenômeno é uma reatualização das primeiras experiências de fusão/separação com a mãe. A ilusão grupal é uma tentativa desesperada de voltar a recriar o estado de fusão e negar a separação. Para não experimentar situação de "o grupo e eu", o grupo produz a ilusão de que "eu sou o grupo", "o grupo sou eu", "todos são um" e "o grupo é todos".

Freud (1921/2013), retomando a teoria de Le Bon, mostra que sejam quem forem os indivíduos que compõem um grupo, por semelhantes ou dessemelhantes que sejam, o fato de haverem sido transformados em um grupo coloca-os na posse de uma espécie de mente coletiva que os faz sentir, pensar e agir de maneira muito diferente daquela pela qual cada membro dele, tomado individualmente, sentiria, pensaria, e agiria, caso se encontrasse em estado de isolamento. O grupo é formado por elementos heterogêneos que por um momento se combinam, exatamente como as células que constituem um corpo vivo, formam, por sua reunião, um novo ser que apresenta características muito diferentes daquelas possuídas por cada uma das células isoladamente.

Este trabalho consiste na discussão de como o fenômeno da autocracia opera nos processos grupais a partir da análise do filme "A Onda" (Gansel, 2008). O objetivo deste estudo é analisar como o contexto sócio-histórico do nazismo constituiu as relações de grupo no filme. A relação de poder estabelecida pelo sistema autocrático sob os seus indivíduos, assim como as razoes pelas quais os participantes de um grupo se deixam influenciar por este assim como pelo seu líder, nortearam as investigações deste trabalho. Como um governo atroz como o de Hitler pode subordinar tantas pessoas? Isto seria possível hoje em dia e onde poderíamos enxergar modelos semelhantes? O estudo dos processos grupais a partir de uma perspectiva psicanalítica, lança sobre o modelo autocrático uma forma de compreensão deste fenômeno.

\section{Método}

Para discutir o fenômeno autocrático, será utilizado o filme "A Onda", juntamente à Barbarói, Santa Cruz do Sul, n.46, p.<67-80>,jan./jun. 2016 
pesquisa teórica por se tratar de um filme que ilustra com clareza o tema especificado, via análise de conteúdo. Este método de pesquisa, descrito por Moraes (1999), é usado para descrever e interpretar o conteúdo de toda classe de documentos de texto, com o objetivo de compreender seus significados num nível que vai além de uma leitura comum. A matéria prima da análise de conteúdo pode constituir-se de qualquer material de comunicação verbal ou não verbal, como cartas, jornais, revistas, livros, relatos, discos, fotografias, entrevistas, filmes e outros.

Fabris (2008) destaca a importância da investigação que utiliza filmes como material empírico. O cinema trata de um texto cultural, que nos ajuda a olhar e conhecer a sociedade em que vivemos, o que contribui na produção de significados sociais. Os filmes contam histórias e analisar tais textos criticamente é uma possibilidade de entender os processos em que foram gestadas, e o modo como essas histórias produzem efeitos nas diferentes culturas em que circulam.

Para esta investigação foi utilizada uma pesquisa teórica, que abordou a temática da influência do grupo sobre o indivíduo, tratando-se de um estudo exploratório, através do levantamento de dados secundários, ou seja, de dados já disponíveis. Algumas cenas do filme foram utilizadas para embasar os conceitos teóricos investigados, portanto, a partir desta integração, o trabalho visou à consecução dos objetivos propostos.

A pesquisa bibliográfica corresponde ao levantamento de toda a bibliografia que já foi publicada acerca de um assunto. Tem como objetivo permitir que o pesquisador analise o material encontrado e manipule estas informações, de forma a definir ou resolver problemas já conhecidos, como também explorar novas áreas, problematizando novas questões. (LAKATOS E MARCONI, 2001). Neste trabalho foi realizada uma pesquisa qualitativa de cunho unicamente bibliográfico, uma vez que os dados aqui analisados e comentados já foram publicados por outros autores em artigos científicos e livros (Gil, 2009).

As fontes dos materiais usados para a produção desta pesquisa foram livros, artigos publicados em periódicos e teses de mestrado, encontrados através de consultas ao catálogo online da Biblioteca Central da PUCRS, ao site Google Acadêmico e à base de dados Scielo, a partir dos descritores "autocracia", "totalitarismo" "psicologia dos grupos", e "processos grupais", durante o período de agosto de 2013 a junho de 2014.

Após encontrar material relevante ao tema proposto o mesmo foi lido de forma critica e analítica. Durante esta leitura, foi feito o fichamento acerca dos pontos de interesse, para facilitar a localização dos trechos na hora da escrita. 
Para a escrita, foi feita uma ligação coerente entre alguns dados do material pesquisado e as reflexões críticas da autora, que guiarão o raciocínio e o entendimento do leitor. A bibliografia utilizada para o presente estudo encontra-se publicada e disponível ao público, o que torna autorizado seu uso para embasar este estudo, desde que devidamente referenciada.

\section{Apresentação}

O filme "A Onda", ou "Die Welle" titulo original em alemão, foi lançado em 2008 e dirigido por Dennis Gansel. A película foi inspirada no livro de Todd Strasser (sob o pseudônimo Morton Rhue) que se baseou na historia real de Ron Jones. Em 1967, em Palo Alto Califórnia, Ron Jones, professor de História, fez um experimento com seus alunos: ele impôs uma ambientação do nazismo em sua classe, seguindo os padrões do partido. O projeto durou uma semana e causou diversos problemas.

No filme de Dennis Gansel, a escola habituada na Alemanha, está oferecendo alguns cursos de uma semana. O professor Rainer Wengel é responsável por ministrar a disciplina de autocracia, pois sua preferência anterior, o anarquismo, seria ministrada por outro professor que se recusou em trocar com Rainer. Seus alunos, parte da terceira geração após a Segunda Guerra Mundial, não acreditam que uma ditadura poderia surgir na Alemanha moderna, então Rainer começa um experimento para mostrar o quão fácil é manipular as massas. A partir deste momento, varias estratégias de liderança nazista são reproduzidas pelo professor. Os alunos representariam o povo, enquanto o professor, o ditador. Foram então instituídos para a sala um slogan (Poder, Disciplina e Superioridade), um símbolo gráfico representando o grupo, e dentre outras coisas como o nome "A onda".

O alunos passam a perceber mudanças em seu comportamento, porem "A Onda" começa a ser levada muito a serio, ultrapassando o nível da interpretação, e sendo vivenciada perigosamente pelos alunos que desenvolvem manifestações de vandalismo na cidade, bem como agressões e opressão àqueles que não são do grupo. Forma-se, então, uma verdadeira autocracia dentro do colégio, excluindo os que não eram pertencentes à "raça" escolhida, e a situação começa a sair de controle. Outros alunos, assim como a mulher de Reiner, se opõem ao movimento, e conseguem perceber o que esta acontecendo, portanto, buscam alertar o professor, que de inicio se recusa a aceitar a idéia de que algo vai mal, até que finalmente cai em si.

O filme tem um desfecho dramático, pois no final, quando Reiner reúne todos os membros de $\mathrm{A}$ Onda, para que estes percebam o quão longe foi o movimento e o quanto os alunos estavam 
sendo manipulados por ele, muitos se recusam a acreditar no termino deste, em especial Tim (Frederick Lau). O aluno saca um revolver e ameaça atirar caso o encerramento do movimento se concretize, então um dos alunos brinca com o aluno dizendo que as balas são de festim, porem Tim dispara e atinge o aluno no peito que cai morto no chão. Logo em seguida, Tim aponta a arma para Rainer, que por sua vez, diz para não atirar em seu líder, que se o matasse ai sim A Onda acabaria de vez. Mais nervoso ainda e percebendo o erro que cometeu, e que A Onda estava praticamente acabada, ele atira em sua própria boca. Rainer observa seu cadáver e os estudantes chocados. Rainer é levado preso pela polícia até a viatura, enquanto os alunos, seus respectivos pais e os professores (incluindo sua esposa) o observam.

\section{Integração}

Logo no início do experimento do professor Reiner, ele faz com os alunos a eleição do líder, que o elegem como tal. O professor diz que o grupo funcionará conforme seu direcionamento, então ou eles participavam, ou poderiam ir embora de sua classe caso não seguissem sua orientação. Pichon Rivière (1991) descreveu quatro tipos de lideranças: autocrática, democrática, laissez-faire, e demagógica. A liderança autocrática habitualmente é exercida por pessoas de características obsessivo-narcisísticas, onde este centraliza as decisões, e impõem o seu ponto de vista, sendo própria de grupos compostos por pessoas inseguras e que não sabem fazer um pleno uso de sua liberdade. A partir desta conceitualização, pode-se pensar

que Reiner procura ser um líder autocrático e impõem regras, como por exemplo, os alunos só falarão quando pedirem permissão e se levantarem.

Pode-se pensar, que a intenção do professor Reiner, claramente é reproduzir o modelo de liderança de Hitler, no entanto, o nazista não foi o único líder autocrático totalitário da historia das nações, e nem é necessário voltar muito no tempo para observar a incidência desta autocracia. Atualmente os estados árabes possuem exemplos bastante fidedignos de lideres totalitários, entre eles o ditador egípcio Hosni Mubarak. No final de janeiro de 2011, Hosni Mubarak renunciou o seu mandato de 30 anos, mas só após uma ininterrupta pressão popular. Mubarak assumiu a presidência do Egito em 1981, desde então, abusos de autoridade, assim como alterações nas leis e códigos do pais passaram a ser constantes. Conforme Faoro (2001) elucidou, a autocracia totalitária domina a vida socioeconômica de uma nação, e reprime toda forma de oposição ao governo e liberdade de expressão de seus indivíduos. Mubarak costumava censurar jornais conforme sua vontade, prender por tempo indeterminado quem o presidente 
considerasse uma "ameaça a ordem publica", assim como opositores do seu regime eram presos e torturados.

Em "A Onda" os alunos passam a se envolver cada vez mais com o grupo, tendo criado inclusive um nome para este, que leva o título do filme. Também estabelecem um uniforme, símbolo, saudação, além de promoverem festas em que apenas os membros de A Onda podem participar. Reiner é exaltado e admirado por seus alunos, e cada vez mais alunos aderem à A Onda, e à classe de autocracia. A diretora da escola também chama Reiner para uma conversa, e elogia o estilo pedagógico do professor. Em uma cena onde Reiner discute com sua mulher, ela diz: "Você gosta de como te admiram, de como encheram tua aula e de como te obedecem", então Reiner responde: "E você não gostaria disso? Você é professora, e o sonho de todo professor é que os alunos o obedeçam", a mulher segue "A questão não é essa, eles te obedecem e você tá manipulando pra tirar vantagem". Além de uma liderança autocrática, Reiner exercia o que Zimerman (1993) chamou de líder narcisista como já exposto anteriormente. Em uma análise sobre o filme, Padilha $(\mathrm{s} / \mathrm{n})$ trabalha com a idéia de como um líder convincente, com discurso sedutor e que aparenta ter as respostas e soluções para os grandes problemas mundiais, consegue capturar a carência de autoridade, fazendo clara analogia ao governo de Hitler.

Uma das formas de poder exercida sob o grupo de alunos utilizada para retratar o governo Hitler, é o que Foucault chamaria de poder disciplinar. Maia (1995) ao articular o conceito desenvolvido por Foucault, afirma que a disciplina trata-se de uma técnica, um dispositivo, ou então por assim dizer, um instrumento de poder; a disciplina exerce seu controle não sobre o resultado de uma ação, mas sobre seu desenvolvimento. A disciplina fabrica assim corpos submissos, exercitados, corpos dóceis. Através do uniforme, saudação, e liderança autocrata de Reiner, o grupo passa a se disciplinarizar conforme o que lhes é ordenado.

A partir da disciplinarização e uniformização do grupo, seus integrantes passam a sentir-se cada vez mais unidos e identificados entre si. Esta identificação gera o sentimento de pertença conforme Pichon-Riviere (1998) elucidou. O grupo seguiu veemente o professor e ganhou forcas através da sensação de segurança e proteção que era fornecida pela a união entre seus membros. Em uma das cenas retratadas no filme, a personagem Karo, namorada do aluno Marco, mostra-se revoltada com o movimento a qual foi uma das poucas que não o aderiu. Karo lê o que um integrante escreveu no site do grupo: "Se eu não entrar eu ficarei sem amigos". Então Marco responde: "A onda significa muito para mim, significa união. Você sabe o que é isso porque você tem uma família legal. Eu não tenho."

O sentimento de pertença também pode ser observado nas cenas de outra personagem do filme, Barbarói, Santa Cruz do Sul, n.46, p.<67-80>, jan./jun. 2016 
no entanto, de forma mais acentuada e patológica, trata-se de Tim, aluno que antes do experimento sentia-se solitário, tendo feito amizades apenas a partir do grupo. Tim é o garoto que protagoniza o final trágico do filme, ao atirar em sua própria boca quando percebe que A Onda havia acabado. Em uma cena, Tim segue Reiner ate sua casa e lhe diz: "To aqui pra te proteger professor". "Vai pra casa" responde Reiner, então Tim argumenta: "Fazer o que em casa? Eles não dão a mínima pra mim." A intensa solidão de Tim era protegida através do grupo, que lhe proporcionava o sentimento de pertença, pois conforme Anzieu (2012) estar em um grupo pode promover a tentativa de recriar a fusão mãe/bebe, portanto o indivíduo não é alguém separado deste grupo e sim sente-se como "eu sou o grupo" conforme o conceito do autor de "ilusão grupal" já citado anteriormente. Desta forma, fica mais claro o entendimento de como um indivíduo pode acabar sendo absorvido por um grupo de pessoas e seu líder, a ponto de abdicar sua individualidade.

Para Padilha (s/n) a constituição de um regime totalitarista ocorre justamente onde um vazio de sentido, significativo, seja percebido. Montingelli (2011) faz uma analogia entre a situação econômico-social da Alemanha pós Primeira Guerra e a situação ontológica e familiar das personagens do filme. Em ambos os casos nota-se um vazio existencial e falta de propósitos; no primeiro, pelas humilhações impostas, no segundo caso, pela falta de estrutura familiar. No caso dos egípcios, sob o comando de Hosni Mubarak, apesar deste não ter sido propriamente um líder popular, o que levou a população aceitar seu governo, segundo Ferabolli (2012) foi a política de medo que fez do mundo árabe o "Outro" absoluto, uma região de fanáticos e intolerantes que deveria ser controlada a todo custo. A permanência de Hosni no poder se legitimava por sua capacidade de "controlar radicais islâmicos", portanto alem do apoio dos EUA, o Egito viveu um período de relativa estabilidade domestica e desenvolvimento econômico, pois Hosni controlava os ataques islâmicos que freqüentemente tem como alvo o lucrativo setor de turismo egípcio.

No caso do nazismo de Hitler assim como Reiner em A Onda, estes ainda fizeram um papel de conciliador das necessidades de pertencimento e identificação. Para a falta de objetivos, criou a perspectiva de objetivos comuns, estabelecendo uma massa de manobra, o que levou a intensa sensação de identificação e segurança individual. Ambos contextos orbitam em torno de uma figura central endeusada; o que, não raro, decai para o controle, manipulação e estimulação do fanatismo como forma de assegurar longevidade a essa situação, uma vez que o poder causa uma atração irresistível. (MONTINGELLI, 2011)

Outro ponto relevante do filme de Dennis Gansel que se relaciona com o governo Hitler, Barbarói, Santa Cruz do Sul, n.46, p.<67-80>,jan./jun. 2016 
são as cenas que mostram os participantes do grupo excluindo todos que não pertencem ao mesmo. Alem da cena já descrita, em que o integrante diz temer ficar sem amigos, Karo testemunha seu irmão na porta da escola dizendo que só entrara quem for da A Onda. Ao reclamar para Reiner, este apóia o comportamento do irmão de Karo dizendo a ela que se não concorda com o movimento a aluna pode mudar de sala.

Segundo Montingelli (2011), assim como os arianos, no filme todos devem ser iguais entre si, havendo uma anulação do indivíduo em prol do coletivismo (nas palavras de uma das personagens: “juntos somos fortes”, portanto nenhum deles iria agir sozinho para não ser considerado fraco). O grupo e o pertencimento que este propiciava, passou a despertar em seus membros uma sensação de poder e invencibilidade. Reiner com seu discurso "união e disciplina geram poder" enfatiza a intolerância e a necessidade de ser forte dentro do contexto. Aqueles que se recusam a fazer parte do movimento, se tornam vitimas de pressão e opressão, pois não participam de seu fortalecimento. Para Melman (2008) a constituição e implantação dos Regimes Totalitários, não trabalham com a possibilidade da subjetividade, o sujeito passa a ser engolfado em uma malha do sistema onde não se torna possível dirigir o olhar para perceber o diferente.

Há neste filme, duas personagens que merecem destaque devido os questionamentos que trazem, tratam-se de Mona e Karo. Quando o professor Wenger questiona os sinais visuais de união de um grupo, e os alunos respondem o uniforme como já mencionado. Lisa, uma das alunas, fala: "Os uniformes eliminam as diferenças sociais", porem Mona rebate "é, mas eliminam a individualidade também". Após a escolha do uniforme, Mona inconformada desiste de continuar participando das aulas de autocracia. Karo por sua vez, aceita a idéia em principio, porem a camisa branca que adquiriu (uniforme eleito) não a deixou confortável e a aluna vai a escola com uma de suas roupas habituais. O namorado Marco questiona porque Karo não esta de camisa branca e esta responde que não gostou, então o rapaz insiste que trata-se de vaidade, ao que Karo finaliza: "Porque eu tenho que explicar o motivo de eu não querer usar uma camisa branca?". Para Freud (1921/2013) dentro de um grupo podem ocorrer mecanismos regressivos levando a uma perda da identidade individual prevalecendo a grupal. Neste movimento, os ideais narcísicos mais primitivos ligados à onipotência, à negação da realidade e à cisão podem predominar no ego, com conseqüente perda ou diminuição do senso crítico e da autonomia individual.

A mudança de comportamento dos alunos conforme "A Onda" progredia, assim como a indiferenciação estabelecida entre eles, é demonstrada em outras cenas, como a de um dos Barbarói, Santa Cruz do Sul, n.46, p.<67-80>,jan./jun. 2016 
momentos finais do filme, em que Reiner lê o que os integrantes do movimento escreveram: "não importa agora quem é o mais bonito, o mais popular, ou quem faz mais sucesso, A Onda nos tornou iguais"; "Quando podemos confiar uns nos outros conquistamos muito mais, mesmo que isso signifique sacrificar a nos mesmos".

É visível a transformação dos alunos, como por exemplo, em outra frase lida pelo professor em que é alegado o seguinte: " Antes eu batia nos outros, quanto mais eu penso nisso vejo como eu era idiota. É muito melhor ser parte de uma causa." Marco também mudou seu comportamento através do grupo, mas neste caso para pior. O namorado de Karo tem uma briga com a garota e acaba por ferir-lhe no rosto. Desesperado, Marco vai até a casa de Reiner, suplicar para que este acabe com A Onda: "Esse negocio da A Onda, me transformou professor Wenger. Eu amo a Karo e mesmo assim eu bati nela." O que nos remete ao que Freud (1921/2013) mencionou a respeito da mudança na maneira de sentir e pensar de uma mesma pessoa isolada ou em grupo.

\section{Considerações finais}

Para muitos, é difícil pensar em algo parecido ao que o ocorreu na Alemanha acontecendo nos dias de hoje, ou então compreender o como foi possível toda uma população participar da manutenção deste governo. No entanto, trata-se de um capitulo recente da historia mundial, e apesar de talvez não possuírem todos os elementos característicos do totalitarismo autocrático de Hitler, ao fazer pesquisas mais apuradas, percebe-se muitas instituições e governos repetindo modelos autocráticos semelhantes, como este trabalho brevemente identificou.

A experiência real do professor Todd Srasser, ocorrida nos anos 70, e retratada pelo filme de Dennis Gansel, ajudou a mostrar neste artigo, alguns aspectos da psique humana que podem levar um grupo de pessoas a aderirem o modelo autocrático. Esta experiência mostrou a possibilidade de jovens supostamente instruídos e sensatos, serem condicionados por motivações inconscientes a agirem de maneira talvez antes não imaginadas por estes.

A influência de combinações tais como do líder autocrático/narcisista e carismático com um grupo carente de sentido e aspirações, levam os seus participantes a se realizarem através do pertencimento e busca de uma causa, mesmo que esta não seja exatamente clara para os envolvidos. A intolerância em relação ao diferente, aquela que causou a morte de inúmeros judeus, homossexuais, e ciganos, não é justificada, mas explicada através da sensação de poder 
que os pertencentes do grupo sentem ao serem parte de um grande numero de iguais, visto que o fortalecimento do grupo através da identificação e padronização, leva também ao fortalecimento individual de seus membros.

O filme A Onda, foi apenas um dos objetos de estudo possíveis para este trabalho, porém, os governos árabes como o de Hosni Murabak citado neste artigo, assim como outras autocracias espelhadas por diferentes continentes, e instituições sociais, sejam elas de ensino, financeiras, políticas, religiosas e outras, também poderiam ter sido analisadas neste contexto. O presente artigo, devido sua limitação estrutural, usou apenas uma fonte de pesquisa, o que não significa que o assunto se esgote no filme e nos conceitos trabalhados, podendo inclusive haver confrontações em relação a estes se analisados em outras situações, ou então um desdobramento mais profundo do que foi estudado.

\title{
THE PHENOMENON OF AUTOCRACY IN A GROUP PROCESS
}

\begin{abstract}
Seeking to raise a debate about autocracy in group operating systems, a literature review was performed to clarify the issue, along with integrated analysis of the film The Wave. The autocrat experience portrayed in the film between teacher and students seems compatible to psychoanalytic group theories that seek to explain how certain types of groups are formed, leader's characteristic, and which unconscious motivations operated in this kind of group. This article revisited the Hitler government, for being one of the main models of totalitarian autocracy of history, and has been taken as the basis for the formation of the group in the film. The social-historical theory and psychoanalysis integrate this work in the same perspective.
\end{abstract}

Keywords: Groups, psychoanalysis, The Wave, Hitler, autocracy, totalitarism.

\section{Referências}

AVILA, L. A. O Eu é plural: grupos: a perspectiva psicanalítica. Vínculo, nº1, v.9. São Paulo, 2009

ANZIEU, D. O Grupo e o Inconsciente - O imaginário grupal. $2^{a} E d$. São Paulo, Casa Do Psicólogo, 2012.

BIGNOTTO, N. Totalitarismo e liberdade no pensamento de Hannah Arendt. Em: Hannah Arendt: diálogos, reflexões e memórias. Belo Horizonte: Editora da UFMG, 2001.

COELHO, R.C. Ciência Política. Florianópolis. Capes, Uab, 2010.

FABRIS, E. H. Cinema e Educação: Um caminho metodológico. Educação e Realidade. Barbarói, Santa Cruz do Sul, n.46, p.<67-8o>,jan./jun. 2016 
$\mathrm{n}^{\circ} 33$, v.1.Porto Alegre, 2008,

FAORO. R. Os donos do poder. $3^{\text {a }}$ Ed, São Paulo. Editora Globo, 2001.

FERABOLLI, S. Entre a revolução e o consenso:

os rumos da Primavera Árabe. Ciencias e Letras. N51, v.1. Porto Alegre, 2012.

FREUD, S. Psicologia das massas e análise do eu. $1^{\text {a }}$ Ed, Porto Alegre. Coleção L\&M Pocket, 2013

GIL, A. C. Como elaborar projetos de pesquisa. 4ªed, São Paulo: Editora Atlas, 2009.

KAËS, R . O grupo e o sujeito do grupo. $2^{\text {a }}$ Ed. São Paulo, Casa do Psicólogo, 2012.

KELSEN, H. A Democracia. $2^{a} E d$. São Paulo: Martins Editora Livraria Ltda, 2000

LANE, S. T. M. Uma análise do processo grupal. Cadernos PUC, n¹1. São Paulo, 1981.

LAKATOS, E. M; MARCONI, M. A. Metodologia do trabalho cientifico: procedimentos básicos, pesquisa bibliográfica, projeto e relatório, publicações e trabalhos científicos.São Paulo: Atlas, 2001.

MAIA, A. C. Sobre a analítica do poder de Foucault. Revista Tempo Social, nº 1-2, v.7. São Paulo, 1995.

MELMAN, C. A Prática Psicanalítica Hoje: Conferências. $1^{a} E d$. Rio de Janeiro: Tempo Freudiano, 2008

MONTINGELLI, D. Os perigos do Holocausto, da xenofobia, do racismo e do fundamentalismo político. Jus Humanum - Revista Eletronica de Ciencias Juridicas e Socias da Universidade Cruzeiro do Sul, nº1, v.1. São Paulo, 2001.

MORAES, M. L. A. Max Pagés: a relação com os laços grupais. Revista Expressão Psi, n², v.5. Pelotas, 2001

MORAES, R. Análise de conteúdo. Revista Educação, n³7, v. 22. Porto Alegre, 1999

PADILHA, S. M; ROSA JUNIOR, N. C. D. F. Violência e Totalitarismos (s/n). Disponivel em http://ged.feevale.br/bibvirtual/Artigo/ArtigoSoniaPadilha.pdf

PICHON-RIVIÈRE, E. O processo grupal. $8^{\circ}$ Ed. São Paulo, Martins Fontes, 1998. 
SARASON, S.B. The psychological sense of community:Prospects for a community psychology. $1^{\circ}$ Ed. San Francisco, Jossey - Bass, 1974.

ZIMERMAN, D. E. Fundamentos Básicos das Grupoterapias. $2^{a} E d$. Porto Alegre, Artmed. 2000

Data de recebimento: 04/09/14

Data de aceite: $23 / 03 / 17$

\section{Sobre a autora:}

Angela Cruz Blauth possui graduação em Psicologia pela Pontifícia Universidade Católica do Rio Grande do Sul (2014). Tem experiência na área de Psicologia Clínica, com ênfase em Psicanálise, Psicologia Educacional e Orientação Profissional. Psicoterapeuta psicanalista em formação por Estudos Integrados de Psicoterapia Psicanalítica - ESIPP. Endereço Eletrônico: psico.angelablauth@gmail.com 